\title{
Analysis of the cattle trade network in the state of Mato Grosso, Brazil
}

\section{Análise da rede de trânsito de bovinos no estado de Mato Grosso, Brasil}

\author{
Rísia Lopes Negreiros ${ }^{1}$; José Henrique Hildebrand Grisi-Filho²; Ricardo Augusto Dias²; Fernando Ferreiraª \\ José Soares Ferreira Neto²; Raul Ossada²; Marcos Amaku² [D \\ ${ }^{1}$ Instituto de Defesa Agropecuária do Estado do Mato Grosso, Cuiabá - MT, Brazil \\ ${ }^{2}$ Universidade de São Paulo, Faculdade de Medicina Veterinária e Zootecnia, Departamento de Medicina Veterinária Preventiva e Saúde \\ Animal, São Paulo - SP, Brazil
}

\begin{abstract}
We characterized the network of cattle movements in Mato Grosso, Brazil-a state responsible for a significant amount of Brazilian beef exports. In this analysis, we were particularly interested in the importance of slaughterhouses in the network of cattle movements, in the characteristics of the trade for different purposes (especially for reproduction, fattening, and slaughter), and about the importance of the main traders. We found that the median distance of all movements was $79.0 \mathrm{~km}$, with an interquartile range between 37.2 and $163.2 \mathrm{~km}$, which suggests a relatively short-range trade pattern; roughly $20 \%$ of the premises purchasing more animals were responsible for $95 \%$ of the animals purchased and $20 \%$ of the premises selling more animals were responsible for $86 \%$ of the animals sold, indicating the importance of the cattle trade hubs. Fitting the degree distribution using a power-law distribution, we obtained a scaling parameter of 2.59, indicating that the cattle movement network of Mato Grosso is less dense than other observed cattle movement networks. The networks for fattening, reproduction, and slaughtering only comprised $73 \%, 56 \%$, and $25 \%$ of all nodes and $52 \%, 30 \%$, and $17 \%$ of all edges, respectively; and slaughterhouses had the highest in-degrees and total degrees, followed by markets and farms, playing the role of main cattle trade hubs. Therefore, slaughterhouses are potentially useful as surveillance points to detect cases, and controlling important trader premises may optimize the use of resources for controlling diseases.
\end{abstract}

Keywords: Animal movements. Brazil. Cattle. Network analysis. Trade.

\section{RESUMO}

Caracterizamos a rede de trânsito de bovinos em Mato Grosso, Brasil - um estado responsável por uma quantidade significativa das exportações brasileiras de carne bovina. Nesta análise, o interesse foi na importância de abatedouros na rede de trânsito de bovinos, nas características do comércio para diferentes finalidades (especialmente para reprodução, engorda e abate), e sobre a importância dos principais comerciantes. Encontramos que a distância mediana de todos os movimentos foi de $79,0 \mathrm{~km}$, com um intervalo interquartil entre 37,2 e $163,2 \mathrm{~km}$, o que sugere um padrão de comércio de alcance relativamente curto; cerca de $20 \%$ dos estabelecimentos que compram mais animais foram responsáveis por $95 \%$ dos animais comprados e $20 \%$ dos estabelecimentos que vendem mais animais foram responsáveis por $86 \%$ dos animais vendidos, o que mostra a importância dos principais comerciantes de bovinos. Ajustando a distribuição de graus usando uma distribuição de lei de potência, obtivemos um parâmetro de escala de 2,59, indicando que a rede de movimentação de bovinos de Mato Grosso é menos densa do que outras redes de trânsito bovino observadas. As redes para engorda, reprodução e abate compreenderam $73 \%, 56 \%$ e $25 \%$ de todos os nós e 52\%, 30\% e $17 \%$ de todas as arestas, respectivamente; e os frigoríficos tiveram os mais altos graus de entrada e totais, seguidos por mercados e fazendas, desempenhando o papel de principais pontos de comércio de gado. Por conseguinte, abatedouros são potencialmente úteis como pontos de vigilância para detectar casos, e o controle de estabelecimentos importantes para o comércio pode otimizar o uso de recursos para o controle de doenças.

Palavras-chave: Trânsito animal. Brasil. Bovinos. Análise de redes. Comércio. 
Correspondence to:

Marcos Amaku

Universidade de São Paulo, Faculdade de Medicina Veterinária

e Zootecnia, Departamento de Medicina Veterinária

Preventiva e Saúde Animal

Av. Prof. Dr. Orlando Marques de Paiva, 87

CEP: 05508-270, São Paulo - SP, Brazil

e-mail:amaku@usp.br

Received: June 29, 2020

Approved: November 04, 2020

How to cite: Negreiros RL, Grisi-Filho JHH, Dias RA, Ferreira F, Ferreira Neto JS, Ossada R, Amaku M. Analysis of the cattle trade network in the state of Mato Grosso, Brazil. Braz J Vet Res Anim Sci. 2020;57(4):e171635. https://doi.org/10.11606/issn.1678-4456.bjvras.2020.171635

\section{Introduction}

The Brazilian cattle herd reached more than 212 million head in 2014 (Portal Brasil, 2015) and is one of the biggest cattle herds in the world, second only to the Indian herd. The state of Mato Grosso is part of the Central West region in Brazil, and, in 2014, was responsible for 33.5\% of the Brazilian cattle herd along with its Central West neighboring states, Mato Grosso do Sul and Goiás (Portal Brasil, 2015). As reported by Barddal et al. (2016), the state of Mato Grosso has 3 million inhabitants and effective beef production of approximately 28 million head. In 2014, meat exports from this state represented 19\% of all exports of Brazilian beef (Associação dos Criadores de Mato Grosso, 2015).

By analyzing the network of animal movements, we may identify farm premises that trade more frequently than others, especially the hubs (central nodes) of the network. These hubs may play the role of infectious disease spreaders because they trade more intensely than the other nodes. Thus, disease control efforts may be focused on these hub premises (Amaku et al., 2015). As shown by Cohen et al. (2003), the immunization of animals in central nodes may enhance the effectiveness of vaccination strategies.

Social network analysis is a valuable framework for studying animal movement networks, as well as the dynamics and control of diseases on these networks (Mweu et al., 2013). In animal movement networks, farm premises are the nodes and animal movements are the edges connecting these nodes. A network of livestock movements may be composed of different types of premises (for instance, beef, dairy, breeder, dealer, live cattle market, auction market, and slaughterhouse). The networks of animal movements, particularly cattle movements, are directed and have a high degree of heterogeneity (Bigras-Poulin et al., 2006).
The degree distribution of some of these networks follows a power law (e.g., Bigras-Poulin et al., 2006; Büttner et al., 2013; Thakur et al., 2016). Therefore, in the analysis of networks of animal movements, it is necessary to consider these characteristics.

Different types of nodes are the key players in the cattle movement network. For example, in a network in Cambodia, the key players were producers who raised their cattle as backyard animals (Poolkhet et al., 2016). Traders were high centrality nodes in a network in Thailand (Noopataya et al., 2015), and markets were the key influential holdings in the network of Danish cattle (Mweu et al., 2013). Markets may play an important role in the spread of infectious diseases, as in the spread of foot-and-mouth disease virus during the 2001 Great Britain epidemic, when the movement of animals through markets was an important factor (Robinson \& Christley, 2007).

Despite the importance of the network of animal movements for the spread of infectious diseases, only a few studies (Amaku et al., 2015; Cipullo et al., 2016; Grisi-Filho et al., 2013; Negreiros et al., 2018; Silva et al., 2017) were performed to characterize the network of animal movements in Brazilian states, using methods of social network analysis (SNA). As far as we know, the network of the state of Mato Grosso in 2007 was the first Brazilian cattle movement network analyzed using SNA methods (Negreiros, 2010). In this article, we present the results of this analysis.

Previous studies of the cattle movement network in the state of Mato Grosso in 2007 have analyzed the spatial distribution of livestock production zones within the state (Grisi-Filho et al., 2013), the cattle trade between and within biomes (Negreiros et al., 2018), and the association between the cattle movement network, herd size, and bovine brucellosis in the state (Cipullo et al., 2016). We have chosen to analyze the same network so that the findings obtained in the present study may help understand the results found in the previous studies and vice-versa.

Thus, the present study aimed at characterizing the cattle movement network in the state of Mato Grosso in 2007, using methods of social network analysis. We calculated several network parameters and the transportation distance, performed an assortativity analysis, compared the importance of the farm premises in the network, and analyzed the degree of distribution. In this analysis, we were particularly interested in the role of slaughterhouses in the network of cattle movements, in the characteristics of the trade for different purposes (especially for reproduction, fattening, and slaughter), and the relative importance of the main traders. 


\section{Materials and Methods}

\section{Database}

In our analysis, we used the cattle movement network of the state of Mato Grosso in 2007, provided by the official veterinary service (Institute of Agricultural Defense of the State of Mato Grosso, INDEA-MT). We extracted data about the origin, destination, the number of animals moved, and movement purpose ("reproduction," "fattening," "market," "exhibition," "work," "slaughter," and "sports"). The premises considered were farms with livestock production, markets (including exhibitions and other animal agglomerations), and slaughterhouses.

\section{Analysis of the network parameters}

We calculated the number of nodes (premises), edges (connections, via animal movement, between nodes), batches, and animals moved, in addition to the network diameter (longest geodesic distance) and the shortest paths between pairs of nodes, for the following networks: all bovine movements ("whole network"); movements only to slaughterhouses ("slaughter only"); the network disregarding movements to slaughterhouses ("without abattoirs"); movements only for fattening purposes ("fattening only"); movements only for reproduction purposes ("reproduction only"); and, finally, with movements for other purposes ("other purposes"), such as exhibitions, markets, sports, and work.

We calculated the following network measures (Newman, 2010): degree (total, incoming, and outgoing); betweenness; closeness; clustering coefficient; PageRank; and ingoing and outgoing contact chain (Nöremark \& Widgren, 2014). A more detailed description of these network measures is presented in the study by Cipullo et al. (2016).

We calculated the geodesic spatial distance (using the WGS84 ellipsoid), in kilometers, for all batches moved, using the R package geosphere.

We also analyzed the total degree (number of neighboring premises) distribution, $P(k)$, given by the relative frequency of nodes with degree $k$ in the network. We fitted a power-law function $P(k)=C e^{-\alpha k}$, where $\alpha$ is a scaling parameter and $C$ is a normalization constant (Amaku et al., 2014). The fitting was carried out using the poweRlaw package in R (Gillespie, 2015). For each group of nodes that share the same degree $k$, we calculated the percentage of nodes of each premises type, to highlight possible differences between degree distributions across premises types.

\section{Assortativity}

We conducted an assortativity analysis to appraise the association between the degree of a node and the average degree of its neighbors. The aim is to analyze whether low- (high-)degree premises are preferentially connected to low- (high-)degree premises (this kind of network is called assortative) or whether low-degree premises are preferentially connected to high-degree premises (revealing a disassortative network).

\section{Pareto principle (80-20 rule)}

The Pareto principle (also known as the 80-20 rule) states that roughly " $80 \%$ of the effects can be attributed to $20 \%$ of causes." In our analysis, we aimed to assess the importance of the hubs (central nodes) of animal trade. Thus, we investigated the percentage of herds responsible for the majority of the cattle movements.

\section{Results and Discussion}

\section{Network parameters}

The cattle movement network had 88,451 nodes (premises), of which 459 (0.52\%) were markets and exhibitions and $116(0.13 \%)$ were slaughterhouses, and 15,965,825 animals were moved in 536,213 batches between nodes.

The number of nodes, edges, batches, animals moved, the diameter of the network, and the mean shortest path for each network is shown in Table 1. Estimates for the network measures are shown in Table 2. The cattle movements network in the state of Mato Grosso is illustrated in Figure 1.

Table 1 - Number of nodes, edges, batches, and animals moved in the network of animal movements from the State of Mato Grosso in 2007

\begin{tabular}{ccccccccccc}
\hline \multirow{2}{*}{ Network } & \multicolumn{2}{c}{$\begin{array}{c}\text { Number of } \\
\text { nodes }\end{array}$} & \multicolumn{2}{c}{ Edges } & \multicolumn{2}{c}{ Batches } & \multicolumn{2}{c}{ Animals moved } & Diameter & $\begin{array}{c}\text { Mean shortest } \\
\text { path }\end{array}$ \\
\hline Whole network & 88,451 & $100 \%$ & 202,235 & $100 \%$ & 536,213 & $100 \%$ & $15,965,825$ & $100 \%$ & 42 & 8.83 \\
Slaughter only & 22,241 & $25 \%$ & 35,027 & $17 \%$ & 254,669 & $47 \%$ & $5,031,387$ & $32 \%$ & 50 & 39.79 \\
Without abattoirs & 86,343 & $98 \%$ & 167,208 & $83 \%$ & 281,544 & $53 \%$ & $10,934,438$ & $68 \%$ & 43 & 9.34 \\
Fattening only & 64,968 & $73 \%$ & 105,212 & $52 \%$ & 178,664 & $33 \%$ & $6,944,103$ & $43 \%$ & 51 & 11.62 \\
Reproduction only & 49,635 & $56 \%$ & 61,199 & $30 \%$ & 90,609 & $17 \%$ & $3,623,514$ & $23 \%$ & 71 & 12.19 \\
Other purposes & 3,641 & $4 \%$ & 5,989 & $3 \%$ & 12,271 & $2 \%$ & 366,821 & $2 \%$ & 42 & 9.61 \\
\hline
\end{tabular}




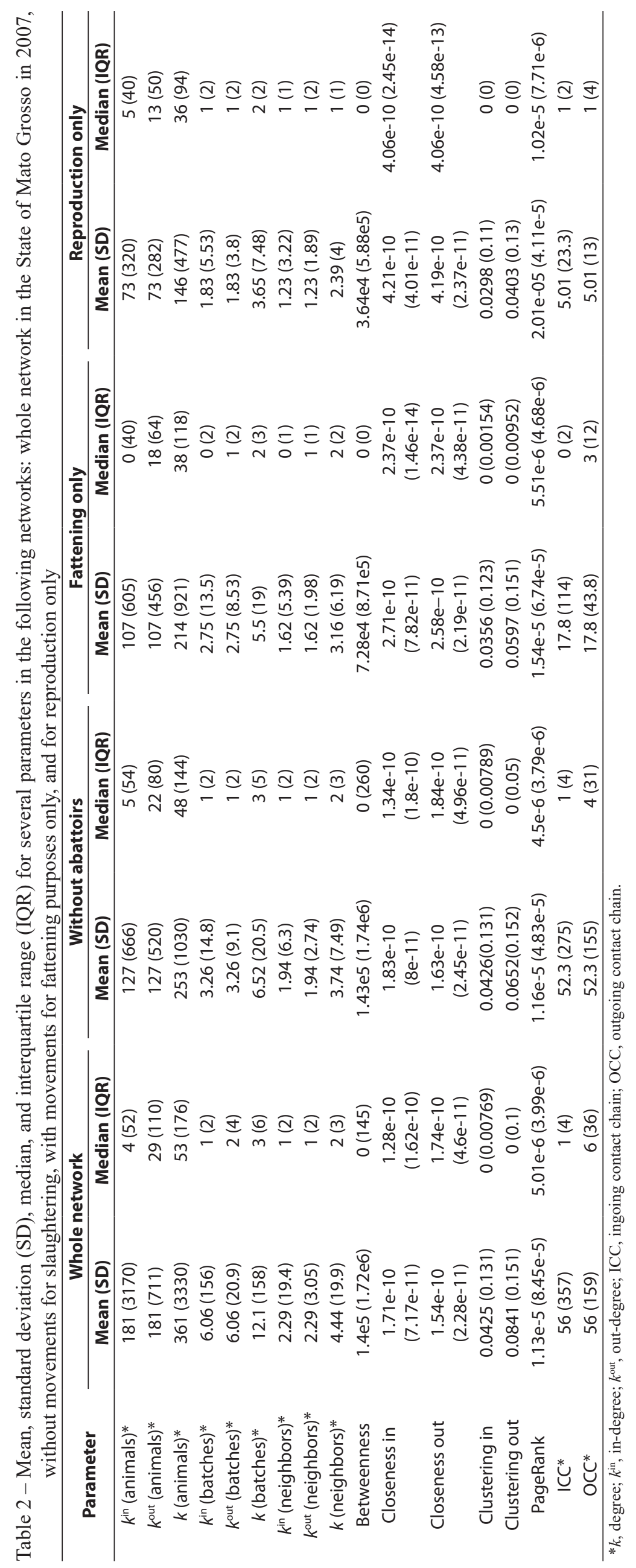




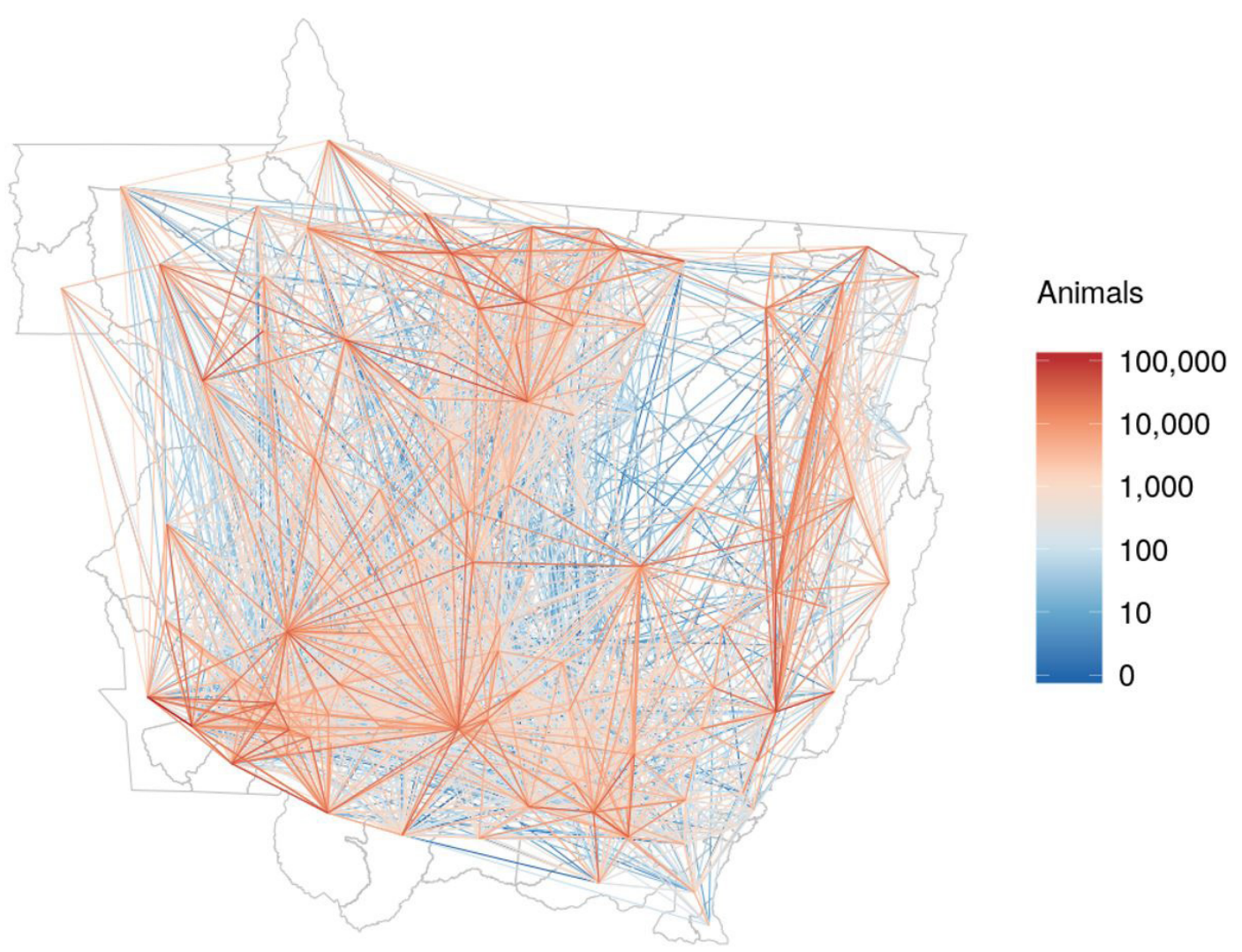

Figure 1 - The network of cattle movements of the state of Mato Grosso, Brazil.

In Table 1, we noticed that the networks for fattening, reproduction, and slaughtering only comprised $73 \%, 56 \%$, and $25 \%$ of all nodes and $52 \%, 30 \%$, and $17 \%$ of all edges, respectively. Notwithstanding $98 \%$ of all premises remained in the network when we exclude the slaughterhouses, $68 \%$ of all animals were moved in this network.

We note that the diameter and the mean shortest path in the whole network and the network without abattoirs are close (Table 1), indicating that the abattoirs do not influence the paths within the network. This outcome is expected because abattoirs play the roles of sinks in the network. We also notice that the slaughtering only network has the greatest mean shortest path.

The mean betweenness centrality for the whole network was $1.4 \mathrm{e} 5$ (standard deviation $(\mathrm{SD})=1.72 \mathrm{e} 6$ ), while the median was 0 (interquartile range $(\mathrm{IQR})=145$ ) (Table 2 ). This result indicates that, although $50 \%$ of all betweenness values were zero (given by the median), and $25 \%$ were between 0 and 145 (third quartile), there were some nodes with very high betweenness values, increasing the mean. On the other hand, when we analyze the network for reproduction only, the mean betweenness is reduced to one-half, and the dispersion is also reduced (as given by the SD and IQR). We have to consider that the number of nodes in this network is reduced (56\% of the nodes in the whole network), which diminishes the number of available paths between the nodes. A similar argument may be extended to the network for fattening only, which involves $73 \%$ of all nodes, and also has a lower mean and SD. However, when we removed the movements for slaughtering from the network, the mean and the SD of the betweenness slightly increase. When the movements for slaughtering were removed from the network, we also withdrew: (a) slaughterhouses, which received movements only for slaughtering and never sent batches of animals (i.e., had betweenness equal to 0 ); and (b) farm premises that moved animals only to slaughterhouses (i.e., premises with betweenness equal to 0 ). Thus, although most of the nodes were in the network without abattoirs (98\%), the remaining $2 \%$ that were removed had betweenness 0 , increasing slightly the mean and the dispersion of this network.

Closeness is greater in the subnets (without abattoirs, fattening only, and reproduction only) than in the whole network. When there is no path between two nodes, a distance equal to the number of nodes in the network is considered in the calculation of closeness. This procedure leads to two effects: impossible paths in the whole network contribute to the calculation of the closeness denominator with a distance of about 80,000 ; in the subnets when a node is removed from the whole network, the contribution to the denominator is removed, increasing the subnet closeness. Even if both unconnected nodes remained in the subnet, 
the contribution to the denominator became smaller (with a distance of about 50,000 for the reproduction only network and about 65,000 for the fattening only network). In general, smaller networks have shorter geodesic distances, which is also accompanied by an increase in closeness.

The mean clustering coefficient is smaller in the fattening only and reproduction only subnets than in the whole network, which presumably suggests that a substantial fraction of the closed triangles in the whole network constitutes movements of mixed purposes. If the number of triangles constituted by movements for the same purpose is high, we would probably observe an increase in the clustering coefficient in specific subnets, because the decrease of the number of nodes also reduces the number of possible triangles, thereby increasing the percentage contribution of each triangle.

Analyzing Table 2, we observed that the mean values of the in-degree, out-degree, total degree, ingoing contact chain, and outgoing contact chain were greater in the whole network than in the subnets. This is partly explained by the fact that the number of nodes in the whole network is greater than the number in the subnets analyzed, so is the trade volume, and partly by the network topology, given that the slaughterhouses are acting as sinks of an intense animal trade for the whole network.

The median geodesic distance for all movements was $79.0 \mathrm{~km}$, with an IQR between 37.2 and $163.2 \mathrm{~km}$. The distribution of the geodesic distances is shown in Figure $\mathrm{S} 1$ of the supporting material.

The fitting of the degree (total, in-degree, and out-degree) distribution using the power law is shown in Figure 2, with each type of predominant premises (farms, markets, and slaughterhouses) represented by a different color. We note that the slaughterhouses have the highest in-degrees and total degrees, followed by markets and farms. The degree distribution also follows a power law for most premises. When the predominant premises type shifts from farms and markets to slaughterhouses, the degree of distribution deviates from the power-law model found, showing that the degree of distribution is also associated with the premises type. In Table 2, we can see that the mean in-degrees (for animals, batches, and neighbors) are higher in the whole network than in the networks in which there are no slaughterhouses (networks without abattoirs, for fattening only, and for reproduction only), which corroborates the role of the slaughterhouses as important sinks in the network.

We note the importance of the slaughterhouses as sinks of the animal movements in the analysis of the degree distribution (Figure 2). In particular, 1,992 farm premises traded exclusively with the slaughterhouses. By visual inspection of Figure 3, we note that the total degree distribution reflects mainly the contribution of the in-degree distribution. The scaling parameter for the total degree distribution was $\alpha=2.59$. In Figure 2C, we observe that the degree distribution without the slaughterhouses is different, with a higher power-law scaling parameter $\alpha_{\text {out }}=3.56$.

The scaling parameter $\alpha$ of real networks usually lies in the range of $1.5<\alpha<3$, although there are exceptions (Clauset et al., 2009). Networks with $\alpha$ values close to 1 are denser than networks with higher values of $\alpha$ (Amaku et al., 2014). Thus, the cattle movement network of Mato Grosso is less dense than the networks from the state of Pernambuco, Brazil (Silva et al., 2017), with a scaling parameter $\alpha=1.88$ for the total degree, and from Denmark (Bigras-Poulin et al., 2006), with scaling parameters for the in-degree and out-degree of $\alpha_{\text {in }}=2$ and $\alpha_{\text {out }}=1.46$, respectively.

Interestingly, in the network of cattle movements in the state of Pernambuco, in the northeast area of Brazil, markets were the most important hubs (Silva et al., 2017). This is probably associated with differences in the production system structure: beef production is an important economic activity in Mato Grosso, with slaughterhouses playing an important role in the cattle production chain, whereas in Pernambuco, there are many subsistence farm premises, with markets playing an important role as a venue for the exchange of cattle.

\section{Assortativity}

The results of the assortativity analysis, depicting the distribution of neighbors' degrees as a function of the node degree, are shown in Figure S2 of the supporting material. In Figure 3, we observe the overall mean value of the neighbors' degrees. The Spearman correlation coefficient for the mean neighbor degree as a function of the node degree was -0.905 . This negative correlation coefficient suggests that the nodes in the Mato Grosso network are mixed in a disassortative way, that is, premises with high degrees are, on average, predominantly connected to low-degree premises and vice versa. However, despite this average behavior, we note that, for nodes with a given degree, their neighbors have a distribution of degrees varying from lowto high-degree neighbors, meaning that low- (and also high) degree nodes are connected to high- and low-degree nodes, but the dispersion of the distribution decreases as the degree of the reference node increases.

\section{Pareto principle ( $80-20$ rule)}

Figure 4 shows the results for the Pareto principle analysis. We observed that roughly $20 \%$ of the premises 

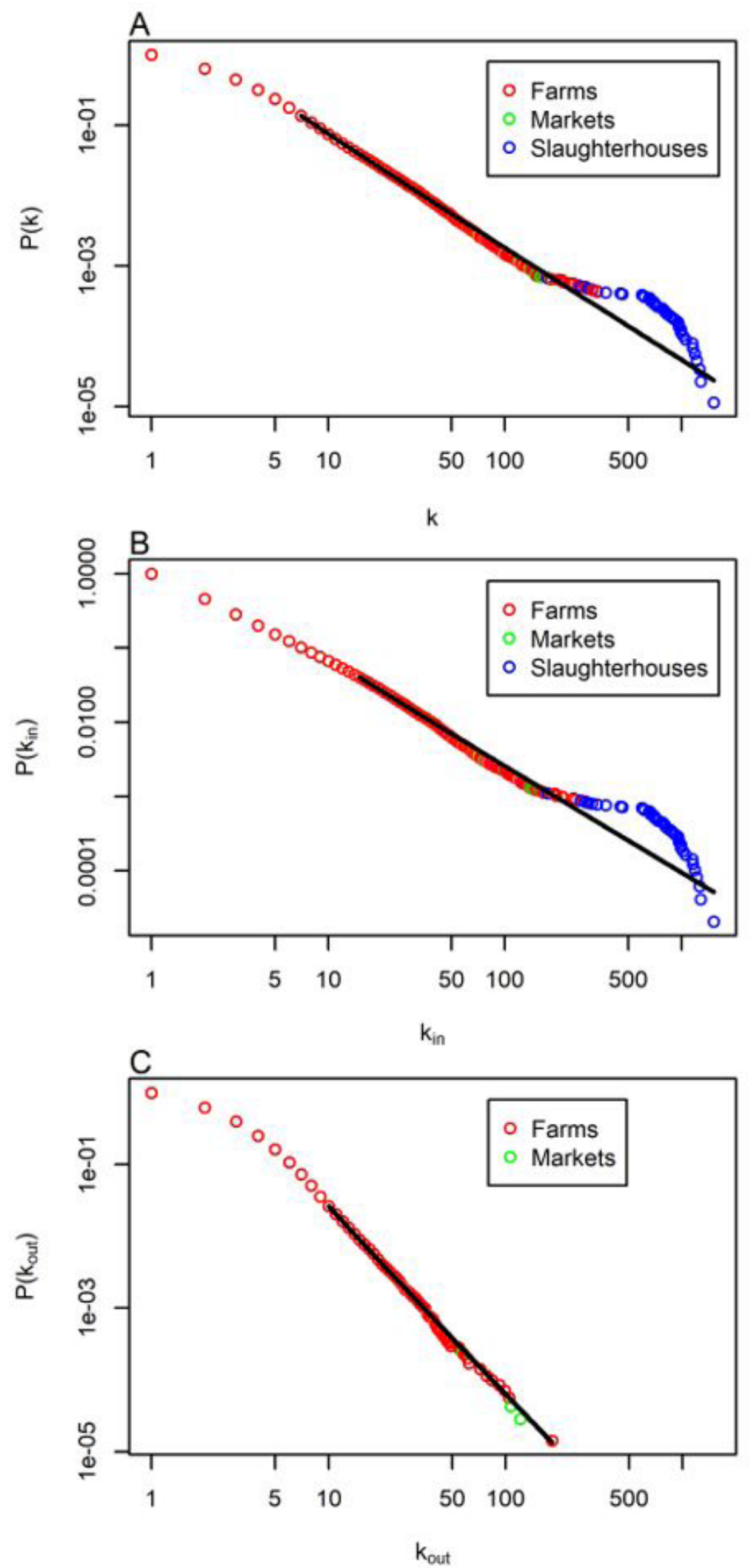

Figure 2 - The distribution of the premises degrees showing the proportion of nodes with a certain degree based on the type of premises (farms, markets, and slaughterhouses) on a logarithmic scale. The line is fitted based on the power law, with a fitting parameter and a minimum value for $k$ used in the fit of: (A) $\alpha=2.59$ and $k_{\min }=7$ for the total degree; (B) $\alpha_{i n}=2.43$ and $k_{\min }=15$ for the in-degree; (C) $\alpha_{\text {out }}=3.56$ and $k_{\min }=10$ for the out-degree.

purchasing more animals were responsible for $95 \%$ of the animals purchased and $20 \%$ of the premises selling more animals were responsible for $86 \%$ of the animals sold. Also, $6 \%$ of the premises (slaughterhouses included) were responsible for $80 \%$ of the animals purchased and $15 \%$ of the premises were responsible for $80 \%$ of the animals sold.

Previous studies of the cattle movement network in Mato Grosso in 2007 have shown that a community detection 


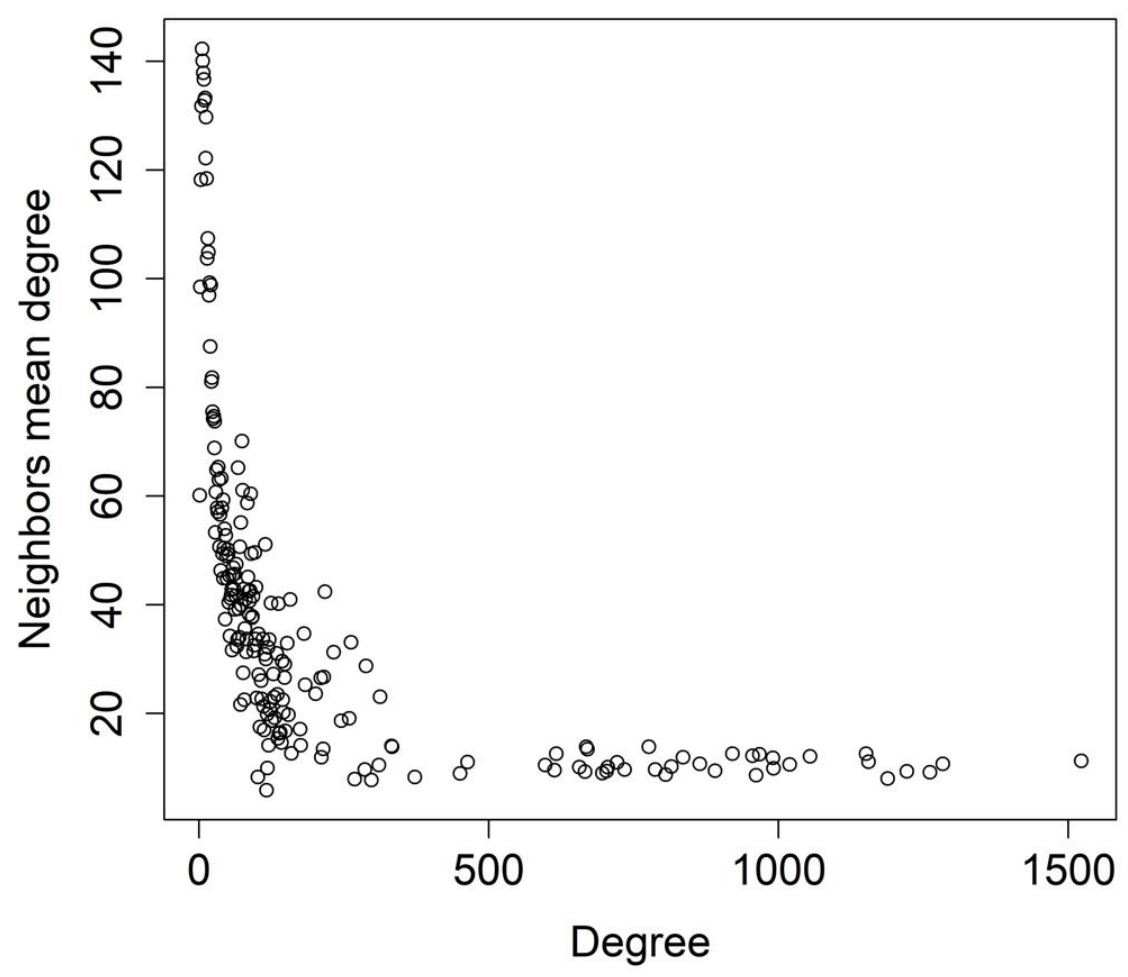

Figure 3 - For each node degree, the overall mean degree of the neighbors.

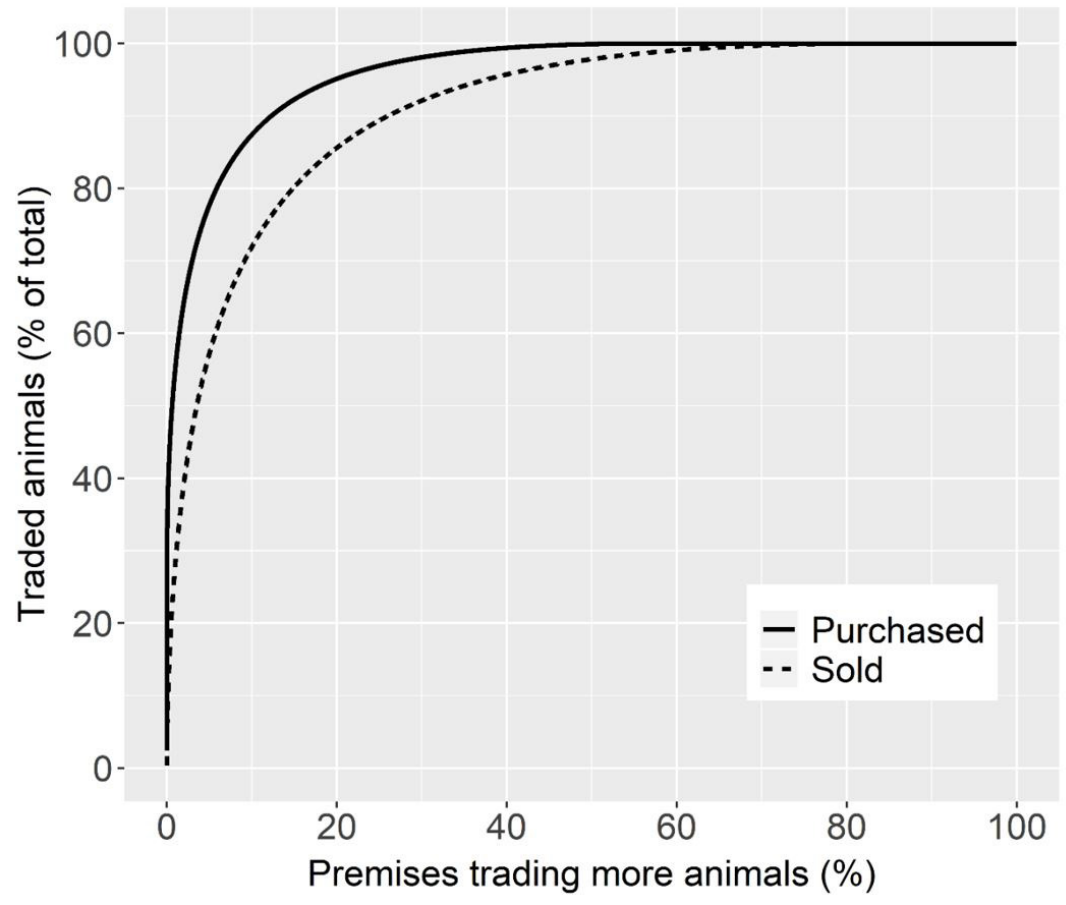

Figure 4 - Traded animals (as a percentage of the total) as a function of the percentage of premises trading more animals.

algorithm applied to the network achieved a network partition showing a clear geographical and commercial pattern (Grisi-Filho et al., 2013). Most of the cattle movement was intrastate and internal movements within each biome were predominant (Negreiros et al., 2018). These findings reflect the distribution of geodesic spatial distances analyzed in the present study. Moreover, an association was noted between herd size and animal trade (Cipullo et al., 2016), both of which could contribute to the spread of infectious diseases, corroborating the importance of the hubs of animal trade. We also found that we can navigate the network searching the hubs using the friendship paradox (Amaku et al., 2015), given that many nodes were connected to hubs. This is related to our analysis of the Pareto principle, which, in this case, gave a ratio of $20 \%$ of premises responsible for $95 \%$ of the movements, surpassing the $80-20$ rule. 
We observed that, on average, high-degree premises trade more intensively with low-degree premises and vice versa. The contact between premises with high and low trade patterns has potential implications for the spread of infectious diseases among herds. Network hubs (nodes with high trading patterns) may spread disease more efficiently; thus, control strategies may be targeted towards hubs. A considerable fraction of low-degree premises are directly connected or close to a hub in the cattle movement network of Mato Grosso, as demonstrated by the analysis using the friendship paradox on this network (Amaku et al., 2015).

\section{Conclusion}

In summary, we found that a relatively small fraction of the farm premises is responsible for most of the cattle movements. As we observed in the analysis of the degree distributions, slaughterhouses were important hubs, followed by markets and big farms.

Analyzing the network of cattle movements in the state of Mato Grosso, we noticed that there were important hubs: $20 \%$ of the premises purchasing more animals were responsible for $95 \%$ of the animals purchased and $20 \%$ of the premises selling more animals were responsible for $86 \%$ of the

\section{References}

Amaku M, Cipullo RI, Grisi-Filho JHH, Marques FS, Ossada R. The friendship paradox in scale-free networks. Appl Math Sci. 2014;8:1837-45. http://dx.doi.org/10.12988/ ams.2014.4288.

Amaku M, Grisi-Filho JHH, Negreiros RL, Dias RA, Ferreira F, Ferreira No JS, Cipullo RI, Marques FS, Ossada R. Infectious disease surveillance in animal movement networks: an approach based on the friendship paradox. Prev Vet Med. 2015;121(3-4):306-13. http://dx.doi.org/10.1016/j. prevetmed.2015.08.002. PMid:26277202.

Associação dos Criadores de Mato Grosso - Acrimat. Informativo mensal da Associação dos Criadores de Mato Grosso. Cuiabá: Acrimat; 2015. no. 52.

Barddal JEI, Quixabeira-Santos JC, Lopes IF, Ferreira No JS, Ferreira F, Amaku M, Dias RA, Telles EO, GrisiFilho JHH, Heinemann MB, Gonçalves VSP, Aguiar DM. Effect of vaccination in lowering the prevalence of bovine brucellosis in the state of Mato Grosso, Brazil. Semina: Ciênc Agrár. 2016;37(5, Suppl. 2):3479-92. http://dx.doi. org/10.5433/1679-0359.2016v37n5Supl2p3479. animals sold, exceeding the 80-20 rule. The implications for surveillance and control are straightforward: slaughterhouses are potentially useful as surveillance points to detect cases and the control of important trader premises may optimize the use of resources for controlling diseases. Therefore, the analysis we performed may be useful for animal health authorities for surveillance purposes.

\section{Conflict of Interest}

The authors declare that they have no competing interests.

\section{Ethics Statement}

This article does not contain any studies with animals performed by any of the authors.

\section{Acknowledgements}

The authors are grateful to INDEA-MT (Institute of Agricultural Defense of the State of Mato Grosso) for providing the databases. The authors acknowledge financial support from CNPq. This study was financed in part by the Coordination of Improvement of Higher Education Personnel - Brazil (CAPES) - Finance Code 001.

Bigras-Poulin M, Thompson RA, Chriel M, Mortensen S, Greiner M. Network analysis of Danish cattle industry trade patterns as an evaluation of risk potential for disease spread. Prev Vet Med. 2006;76(1-2):11-39. http://dx.doi. org/10.1016/j.prevetmed.2006.04.004. PMid:16780975.

Büttner K, Krieter J, Traulsen A, Traulsen I. Static network analysis of a pork supply chain in Northern Germany: characterisation of the potential spread of infectious diseases via animal movements. Prev Vet Med. 2013;110(3-4):41828. http://dx.doi.org/10.1016/j.prevetmed.2013.01.008. PMid:23462679.

Cipullo RI, Grisi-Filho JHH, Dias RA, Ferreira F, Ferreira No JS, Gonçalves VSP, Marques FS, Negreiros RL, Ossada R, Amaku M. Cattle movement network, herd size, and bovine brucellosis in the State of Mato Grosso, Brazil. Semina: Ciênc Agrár. 2016;37(5, Suppl. 2):3777-92. http:// dx.doi.org/10.5433/1679-0359.2016v37n5Supl2p3777.

Clauset A, Shalizi CR, Newman MEJ. Power-law distributions in empirical data. SIAM Rev. 2009;51(4):661-703. http:// dx.doi.org/10.1137/070710111. 
Cohen R, Havlin S, Ben-Avraham D. Efficient immunization strategies for computer networks and populations. Phys Rev Lett. 2003;91(24):247901. http://dx.doi.org/10.1103/ PhysRevLett.91.247901. PMid:14683159.

Gillespie CS. Fitting heavy tailed distributions: the poweRlaw package. J Stat Softw. 2015;64(2):1-16. http:// dx.doi.org/10.18637/jss.v064.i02 .

Grisi-Filho JHH, Amaku M, Ferreira F, Dias RA, Ferreira No JS, Negreiros RL, Ossada R. Detecting livestock production zones. Prev Vet Med. 2013;110(3-4):304-11. http://dx.doi. org/10.1016/j.prevetmed.2012.12.013. PMid:23434375.

Mweu MM, Fournié G, Halasa T, Toft N, Nielsen SS. Temporal characterisation of the network of Danish cattle movements and its implication for disease control: 2000-2009. Prev Vet Med. 2013;110(3-4):379-87. http://dx.doi.org/10.1016/j. prevetmed.2013.02.015. PMid:23473852.

Negreiros RL, Grisi-Filho JHH, Dias RA, Ferreira F, Homem VSF, Ferreira No JS, Ossada R, Amaku M. Cattle trade between and within biomes in the state of Mato Grosso, Brazil. Pesq Vet Bras. 2018;38(11):2023-8. http://dx.doi. org/10.1590/1678-5150-pvb-5661.

Negreiros RL. Caracterização e análise da rede de movimento de bovinos no Estado de Mato Grosso [thesis]. São Paulo: Faculdade de Medicina Veterinária e Zootecnia, Universidade de São Paulo; 2010. http://dx.doi.org/10.11606/T.10.2010. tde-12062012-144132.

Newman MEJ. Networks: an introduction. Oxford: Oxford University Press; 2010. http://dx.doi.org/10.1093/ acprof:oso/9780199206650.001.0001.

Noopataya S, Thongratsakul S, Poolkhet C. Social network analysis of cattle movement in Sukhothai Province, Thailand: a study to improve control measurements. Vet Med Int. 2015;2015:587252. http://dx.doi.org/10.1155/2015/587252. PMid:26881182.
Nöremark M, Widgren S. EpiContactTrace: an R-package for contact tracing during livestock disease outbreaks and for risk-based surveillance. BMC Vet Res. 2014;10(1):71. http://dx.doi.org/10.1186/1746-6148-10-71. PMid:24636731.

Poolkhet C, Kasemsuwan S, Seng S, Keartha C, Sokmao C, Shin M, Kalpravidh W, Hinrichs J. Social network analysis of cattle movement in Kampong Cham, Kampong Speu and Takeo, Cambodia. Acta Trop. 2016;159:44-9. http://dx.doi. org/10.1016/j.actatropica.2016.03.027. PMid:27012718.

Portal Brasil. Rebanho bovino brasileiro cresce e chega a 212,3 milhões de cabeças de gado [Internet]. 2015 [cited 2016 Nov 8]. Available from: http://www.brasil.gov.br/ economia-e-emprego/2015/10/rebanho-bovino-brasileirocresce-e-chega-a-212-3-milhoes-de-cabecas-de-gado

Robinson SE, Christley RM. Exploring the role of auction markets in cattle movements within Great Britain. Prev Vet Med. 2007;81(1-3):21-37. http://dx.doi.org/10.1016/j. prevetmed.2007.04.011. PMid:17482296.

Silva JL Jr, Almeida EC, Corrêa FN, Lima PRB, Ossada R, Marques FS, Dias RA, Ferreira F, Ferreira No JS, GrisiFilho JHH, Amaku M, Manso Fo HC, Silva JCR. Livestock markets play an important role in the cattle movement network in Pernambuco, Brazil. Braz J Vet Res Anim Sci. 2017;54(3):225-37. http://dx.doi.org/10.11606/issn.16784456.bjvras.2017.124303.

Thakur KK, Revie CW, Hurnik D, Poljak Z, Sanchez J. Analysis of swine movement in four Canadian regions: network structure and implications for disease spread. Transbound Emerg Dis. 2016;63(1):e14-26. http://dx.doi. org/10.1111/tbed.12225. PMid:24739480.

Financial Support: CNPq. This study was financed in part by the Coordination of Improvement of Higher Education Personnel - Brazil (CAPES) - Finance Code 001. 


\section{Supplementary Material}

The distribution of the geodesic distances observed in the cattle movement network of the state of Mato Grosso is shown in the boxplot of figure $\mathrm{S} 1$.

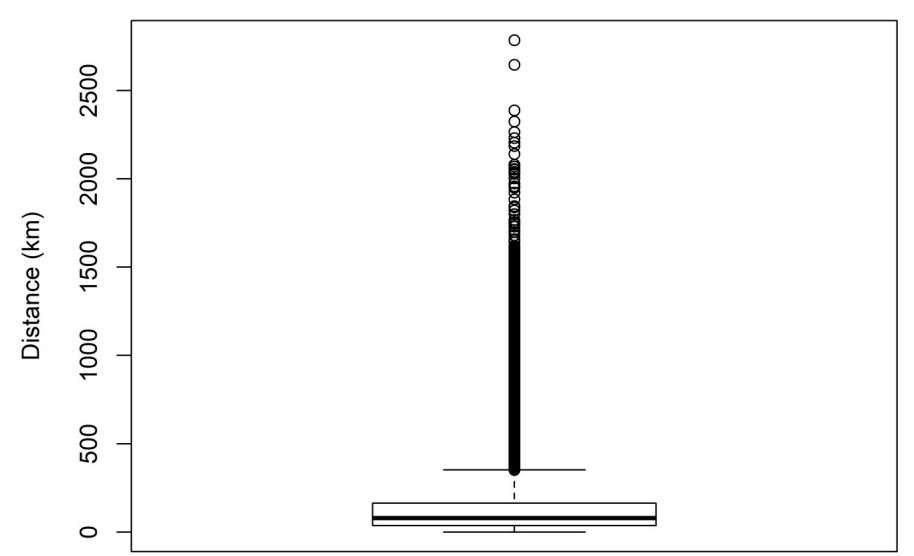

Figure S1. Boxplot of the geodesic spatial distance (in kilometers) for all batches moved.

The results of the assortativity analysis, depicting the distribution of neighbors' degrees as a function of the node degree, are shown in figure $\mathrm{S} 2$.

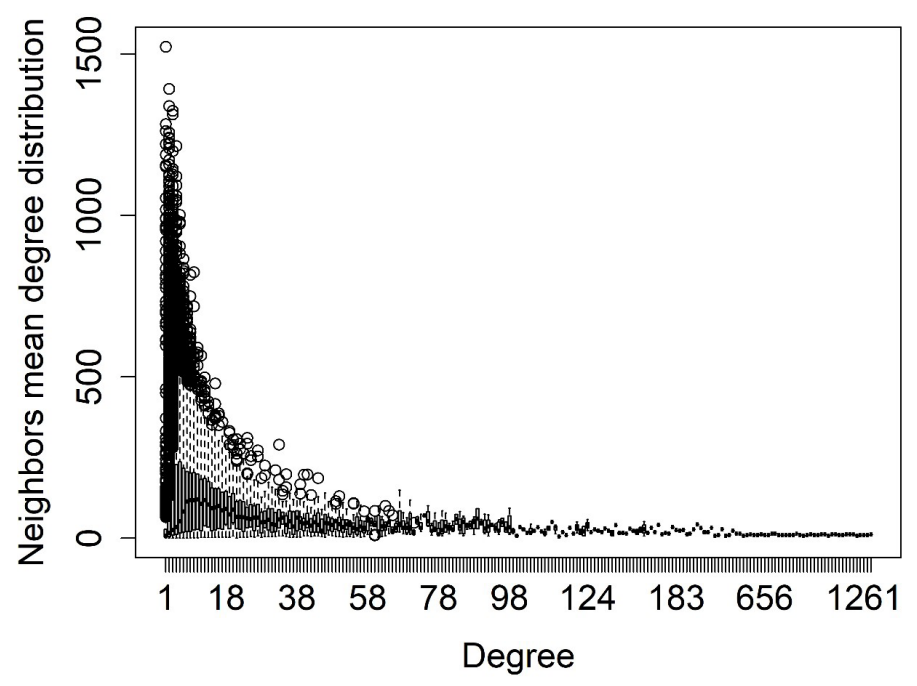

Figure S2. For each node degree, a boxplot showing the neighbors mean degree distribution. Note that the x-axis is not continuous, showing only the available degree values equally spaced. 